\title{
Intraoperative decrease in pulse oximeter read- ings following injection of isosulfan blue
}

Robert W. H oskin MD PhD,* Robert Granger M D $\dagger$

Purpose: Sentinel lymph node mapping, involving injection of isosulfan blue dye around a tumour, is beginning to be used in patients with carcinoma of the breast. Absorption of the dye into the circulation may interfere with pulse oximetry, causing falsely low readings. This report describes changes in pulse oximeter readings following injection of isosulfan blue for sentinel lymph node mapping in a patient with carcinoma of the breast.

Clinical Features: An 83-yr-old female patient underwent sentinel node biopsy of the axilla followed by partial mastectomy for carcinoma of the left breast. Isosulfan blue was injected in the area of the tumour in the left breast. The $\mathrm{SpO}_{2}$ began to decrease $15 \mathrm{~min}$ after dye injection, reaching a nadir of 89-90\% $30 \mathrm{~min}$ after injection. Arterial blood gas analysis showed normal arterial partial pressure of oxygen. Pulse oximeter readings did not return to normal until more than six hours after dye injection.

Conclusion: Review of the literature reveals a small number of case reports of similar occurrences of low pulse oximeter readings following injection of isosulfan blue or patent blue dye for lymphatic mapping. Data from these reports and the case described here suggest that the latency, magnitude and duration of effect on pulse oximeter readings following injection of these dyes is highly variable. It is important to rule out other causes of low pulse oximeter readings when this effect occurs; no rmal oxygenation can be verified with arterial blood gas analysis. C 0 oximetry can be done to rule out methemoglo binemia as a cause of decreased $\mathrm{SpO}_{2}$.

O bjectif : La cartographie des ganglions lymphatiques de Troisier, comportant l'injection de colorant bleu iso sulfane autour d'une tumeur, est utilisée depuis peu dans les cas de cancer du sein. L'absorption du colorant dans la circulation peut interférer sur l'oxymétrie de pouls en causant de fausses valeurs à la baisse. Le présent article décrit ce genre de changements survenus à la suite de l'injection de colorant bleu isosulfane pour la cartographie d'un ganglion de Troisier chez une patiente atteinte d'un cancer du sein.

Éléments cliniques : Une femme de 83 ans a subi, à l'aisselle, une biopsie d'un ganglion de Troisier suivie d'une mastectomie partielle pour un cancer du sein gauche. Du bleu isosulfane a été injecté autour de la tumeur. La $\mathrm{SpO}_{2}$ a commencé à baisser 15 min après l'injection du colorant et a atteint un creux de 89-90\%, 30 min après l'injection. La gazométrie artérielle a montré une $\mathrm{SpO}_{2}$ no rmale. Les valeurs de l'oxymétrie pulsée sont revenues à la normale plus de six heures après l'injection de colorant.

Conclusion : $0 \mathrm{n}$ retrouve peu de cas documentés de baisse semblable des valeurs d'oxymétrie pulsée après l'injection de bleu isosulfane ou de colorant bleu spécial pour la cartographie lymphatique. Les données recueillies laissent croire que le temps de latence, l'importance et la durée de l'effet des valeurs de l'oxymétrie pulsée réalisée après une injection de ces colorants sont très variables. II faut exclure d'autres causes de la baisse des relevés d'oxymétrie quand cet effet se manifeste; l'oxygénation normale peut se vérifier par la gazométrie artérielle. La co-oxymétrie peut permettre d'écarter la possibilité de méthémoglobinémie comme cause de la baisse de $\mathrm{SpO}_{2}$. 


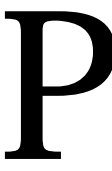

U LSE oximetry relies on the differing absorption of red light by oxyhemoglobin and deoxyhemoglobin, allowing calculation of the percentage of hemoglobin that is saturated with oxygen $\left(\mathrm{SpO}_{2}\right)$. Any substance which absorbs light in the red wavelengths may interfere with the ability of a pulse oximeter to measure oxygen saturation accurately. Dyes such as methylene blue and patent blue five have been reported to cause artificially low $\mathrm{SpO}_{2}$ readings. ${ }^{1-5}$

Recently, isosulfan blue (Lymphazurin $1 \%$ ) has begun to be used to facilitate sentinel lymph node biopsy for carcinoma of the breast. In this technique, dye is injected into the area surrounding the tumour. $D$ ye is absorbed into the lymphatics and causes visible discolouration of the lymphatic channels and nodes draining the area of the tumour. Selective biopsy and histopathological analysis of lymph nodes stained by the dye ("sentinel nodes") may provide diagnostic information of equal value to that provided by more extensive axillary node biopsy. O ne report has been published of intraoperative decrease in $\mathrm{SpO}_{2}$ following injection of isosulfan blue into the uterine cervix. ${ }^{6}$ Reports of this dye's ability to affect pulse oximetry during breast surgery have not appeared in the literature to date. Therefore, report of a case in which isosulfan blue was used intraoperatively for sentinel node biopsy for carcinoma of the breast is presented below.

\section{Case report}

An 83-yr-old woman with biopsy-proven adenocarcinoma of the left breast was booked to have a sentinel node biopsy of the left axilla followed by a partial left mastectomy. General anesthesia was induced with propofol and fentanyl and maintained with desflurane, oxygen and nitrous oxide. Inspired fraction of oxygen was maintained at 0.40 . M uscle relaxation was maintained with rocuronium. The patient was hemodynamically stable and $\mathrm{SpO}_{2}$, measured with an O hmeda RGM 5250 analyzer, remained at $98-99 \%$, The surgeon injected $5 \mathrm{ml}$ of $1 \%$ isosulfan blue (Lymphazurin $1 \%$ U.S. Surgical Corporation, Norwalk, CT) around the tumour mass, aspirating carefully to avoid intravascular injection. Fifteen minutes after the dye injection, the pulse oximeter reading began to decrease, reaching a minimum of $89-90 \% 30$ min after the injection. Blood pressure and heart rate remained stable. $O$ ther causes of intraoperative desaturation such as pneumothorax, malposition of the endotracheal tube or bronchospasm were ruled out clinically. A portion of the patient's face was uncovered, revealing a greyish discolouration of the skin. Arterial blood gas analysis performed 35 min after dye injection revealed a pH of 7.427, $\mathrm{PaCO}_{2}$ of $39.9 \mathrm{~mm} \mathrm{H} \mathrm{g}, \mathrm{PaO}_{2}$ of $190.2 \mathrm{~mm} \mathrm{H} \mathrm{g}, \mathrm{HCO}_{3}$ of $26.3 \mathrm{mEq} \cdot \mathrm{l}^{-1}$ and $\mathrm{O}_{2}$ satu- ration $\left(\mathrm{SaO}_{2}\right)$ of $99.3 \%$ with inspired oxygen fraction of 0.4 . Co-oximetry was not available.

At the completion of surgery $90 \mathrm{~min}$ after the dye injection, $\mathrm{SpO}_{2}$ was measured as $93 \%$. The patient was stable in the recovery room and was transferred to the surgical ward on oxygen via nasal cannula at $2 \mathrm{I} \cdot \mathrm{min}^{-1}$. Pulse oximetry measurement on the ward showed that the patient's $\mathrm{SpO}_{2}$ returned to $99 \%$ by seven hours following dye injection. The greyish discolouration of her skin was beginning to fade by this time.

\section{Discussion}

Pulse oximeters use two wavelengths of light, usually 660 and $940 \mathrm{~nm}$, to determine oxyhemoglobin content of blood via a spectrophotometric process. Pulse oximeters may be unable to accurately determine oxyhemoglobin content in the presence of dyes which absorb red light (for example, isosulfan blue which has its peak absorption at $646 \mathrm{~nm}),{ }^{6}$ or in the presence of carboxyhemoglobin or methemoglobin. M easurement of arterial oxygen saturation $\left(\mathrm{SaO}_{2}\right)$ and $\mathrm{PaO}_{2}$ of an arterial blood sample using a blood gas analyzer permits differentiation between decreases in measured $\mathrm{SpO}_{2}$ due to absorption of the dye into the circulation and true decreases in $\mathrm{SpO}_{2}$. In addition, some blood gas analyzers incorporate co-oximeters which use four or more light wavelengths in order to differentiate among oxyhemoglobin, deoxyhemoglobin, carboxyhemoglobin and methemoglobin. Co-oximetry would allow methemoglobinemia to be ruled out as a cause of spurious decreases in $\mathrm{SpO}_{2}$. This may be relevant as methylene blue may cause methemoglobinemia when administered in high doses, although there is no mention in the literature of isosulfan blue causing this effect.

M ost previous reports of changes in $\mathrm{SpO}_{2}$ resulting from dyes have described transient decreases in $\mathrm{SpO}_{2}$ which resolved in minutes, ${ }^{1,4}$ although $\mathrm{M}$ orell et al. reported a decrease in $\mathrm{SpO}_{2}$ of several hours' duration following intradermal injection of patent blue dye. ${ }^{5} \mathrm{~T}$ he only other report of changes in $\mathrm{SpO}_{2}$ after injection of isosulfan blue described a decrease in $\mathrm{SpO}_{2}$ from $98 \%$ to $89-90 \%$ beginning five minutes after injection of the dye into the uterine cervix and lasting for $10 \mathrm{~min}^{6}{ }^{6} \mathrm{In}$ the patient described in the present report, $\mathrm{SpO}_{2}$ did not return to normal until more than six hours after the dye had been injected. The reason for the longer duration of the dye's effect on $\mathrm{SpO}_{2}$ in the present case is uncertain. Coleman et al. ${ }^{6}$ suggested that, as isosulfan blue is eliminated primarily by biliary excretion, patients with impaired hepatobiliary function may demonstrate prolonged duration of action of effects of the dye when absorbed intravascularly. While liver function tests were not done on the patient described in the present report, 
she had no history of hepatic or biliary disease and no clinical findings to suggest that this may have been the case. It is possible that in previous reports the absorption of dye may have occurred over a brief period of time, producing in effect an intravenous bolus of dye, whereas in the present case absorption may have continued over a more prolonged period of time.

The value of sentinel node biopsy in predicting axillary disease in patients with carcinoma of the breast is uncertain. A multicentre NSABP (N ational Surgical Adjuvant Breast and Bowel Project) study is underway to evaluate this. If the sensitivity and specificity of sentinel node biopsy prove to be high, it is not unreasonable to expect that most axillary node dissections will be replaced by sentinel node biopsies. Therefore, the type of incident described in this report will probably become increasingly common. H owever, the frequency with which decreased $\mathrm{SpO}_{2}$ occurs following injection of isosulfan blue into the breast has not been reported.

Finally, although dye absorption may be suspected as the cause of an intraoperative decrease in $\mathrm{SpO}_{2}$ it is important to rule out causes of real arterial hypoxemia. In the case reported here, checking the $\mathrm{F}_{1} \mathrm{O}_{2}$ displayed on the $\mathrm{O}$ hmeda 5250 gas analyzer and the $\mathrm{O}_{2}$ analyzer on the anaesthesia machine did not indicate delivery of a hypoxic gas mixture. Increasing the $\mathrm{F}_{1} \mathrm{O}_{2}$ to 1.0 to rule out delivery of a hypoxic gas mixture could also be considered, although this was not done in the case reported here. Integrity of the anesthetic breathing circuit should be checked. Inadvertent endobronchial intubation should be ruled out by checking for bilateral breath sounds and verifying that the endotracheal tube is appropriately positioned. A suction catheter can be passed down the tube to rule out kinking or obstruction. Pneumothorax should be ruled out by checking for equal air entry bilaterally, absence of tracheal deviation, and absence of hyperresonance on percussion of the chest. Chest X-ray can be performed if necessary. If pneumothorax is suspected, administration of nitrous oxide should be discontinued and, if tension pneumothorax is suspected, needle decompression of the affected hemithorax should be performed immediately. Breath sounds should be auscultated for expiratory wheeze or prolongation of the expiratory phase, and peak inspira tory pressure and shape of the expired $\mathrm{CO}_{2}$ waveform should be checked to rule out bronchospasm. Causes of ventilation-perfusion mismatch such as atelectasis or pulmonary edema must be ruled out. The pulse oximeter probe may be replaced or moved to another site on the patient to rule out probe malfunction or poor sensing due to local hypoperfusion or vasoconstriction.

In summary, a case is presented in which intraoperative decrease in $\mathrm{SpO}_{2}$ occurred following injection of isosulfan blue dye into the breast for sentinel lymph node mapping. The most likely explanation for this change is absorption of dye into the circulation from the injection site. Arterial blood gases showed $\mathrm{PaO}_{2}$ and $\mathrm{SaO}_{2}$ consistent with the oxygen delivery, confirming the suspicion that the pulse oximeter was delivering falsely low readings. H owever, when intraoperative desaturation occurs, it is important to rule out possible causes of desaturation such as pneumothorax, bronchospasm or endotracheal tube malpositioning. The duration of the effect on $\mathrm{SpO}_{2}$ in this patient was greater than six hours, much longer than the five minutes duration reported by Coleman et al. ${ }^{6}$ following isosulfan blue injection into the cervix. Data from the present case and others reported in the literature $e^{3,5,6}$ indicate that, following dye injection for lymphatic mapping, the magnitude and duration of effect on $\mathrm{SpO}_{2}$ are highly variable.

\section{Addendum}

During revision of this case report, another incident of intraoperative desaturation following administration of isosulfan blue for axillary sentinel node mapping was observed in another hospital. The $\mathrm{SpO}_{2}$ decreased from $99 \%$ to $89 \%$ despite increasing inspired $\mathrm{O}_{2}$ from $40 \%$ to $100 \%$ Aterial blood gas analysis with co-oximetry was available at this hospital, and showed a $\mathrm{PaO}_{2}$ of $449 \mathrm{~mm}$ $\mathrm{Hg}$ and methemoglobin, expressed as a fraction of total hemoglobin, of 0.005 (normal range 0 to 0.020 ). This demonstrates that co-oximetry was able to rule out methe moglobinemia as a cause of decreased $\mathrm{SpO}_{2}$ in this patient.

\section{References}

1 Scheller, M S, U nger RJ, K elner MJ. Effects of intravenously administered dyes on pulse oximetry readings. Anesthesiology 1986; 65: 550-2.

2 K essler MR, Eide T, H umayun B, Poppers PJ. Spurious pulse oximeter desaturation with methylene blue injection. Anesthesiology 1986; 65: 435-6.

3 M cEwan, D, Lam K. O ximetry and patent blue five dye (Letter). Anaesth Intensive Care 1997; 25: 587-8.

4 Saito S, Fukura H, Shimada H, Fujita T. Prolonged interference of blue dye "patent blue" with pulse oximetry readings. Acta Anaesthesiol Scand 1995; 39: 268-9.

$5 \mathrm{M}$ orel $\mathrm{R} \mathrm{C}, \mathrm{H}$ eyneker $\mathrm{T}, \mathrm{K}$ ashtan $\mathrm{HI}, \mathrm{R}$ uppe $\mathrm{C}$. False desaturation due to intradermal patent blue five dye. Anesthesiology 1993; 78: 363-4.

6 Coleman R L, Whitten CW, O'Boyle J, Sidhu B. $U$ nexplained decrease in measured oxygen saturation by pulse oximetry following injection of Lymphazurin $1 \%$ (isosulfan blue) during a lymphatic mapping procedure. J Surg Oncol 1999; 70: 126-9. 